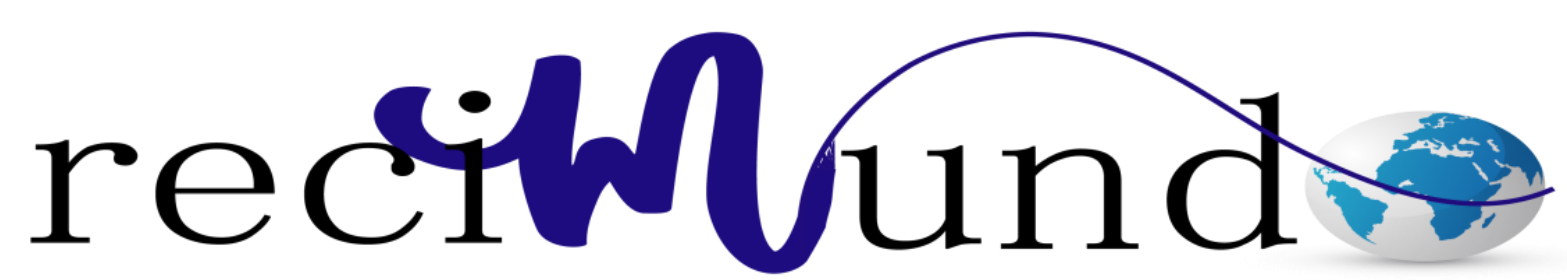

Revista Científica Mundo de la Investigación y el Conocimiento

\author{
Washington Enrique Pazmiño Gavilánez a; Mariella Ginela Parrales Higuera b; \\ Lorena Isabel Muñoz Oviedo ${ }^{c}$; Veronica Alexandra Merchan Jacome ${ }^{d}$
}

Habilidades directivas fundamentales en la administración pública

Fundamental management skills in public administration

Revista Científica Mundo de la Investigación y el Conocimiento. Vol. 3 núm.3. Esp., noviembre, ISSN: 2588-073X, 2019, pp. 682-705

DOI: $10.26820 /$ recimundo/3.(3.Esp).noviembre.2019.682-705

URL: http://recimundo.com/index.php/es/article/view/633

Código UNESCO: 5909 Administración Publica

Tipo de Investigación: Artículo de Revisión

(C) RECIMUNDO; Editorial Saberes del Conocimiento, 2019

Recibido: 15/09/2019 Aceptado: 23/10/2019 Publicado: 30/11/2019

Correspondencia: wpazmino@utb.edu.ec

a. Magister Ejecutivo en Dirección de Empresas con Énfasis en Gerencia Estratégica; Ingeniero Comercial; Universidad Técnica de Babahoyo; Babahoyo, Ecuador; wpazmino@utb.edu.ec

b. Magister en Administración de Empresas; Ingeniera Comercial; Universidad Técnica de Babahoyo; Babahoyo, Ecuador; maly2367@hotmail.com

c. Magister en Administración de Empresas; Diploma Superior en Docencia Universitaria; Ingeniera Comercial; Universidad Técnica de Babahoyo; Babahoyo, Ecuador; marigin@ hotmail.es

d. Magister en Administración de Empresas; Diploma Superior en Docencia Universitaria; Economista; Universidad Técnica de Babahoyo; Babahoyo, Ecuador; veronicamerchanjacome@yahoo.com 


\section{Habilidades directivas fundamentales en la administración pública}

Vol. 3, núm. 3 Esp., (2019)

Washington Enrique Pazmiño Gavilánez; Mariella Ginela Parrales Higuera; Lorena Isabel

Muñoz Oviedo; Veronica Alexandra Merchan Jacome

\section{RESUMEN}

Con fines didácticos se desarrolla un análisis conceptual de los términos; Gestión, Gerencia, Dirección, Gobernación o Gobernanza, Management y Administración, para el buen desarrollo, supervivencia e integración de una empresa al mercado competitivo, se realizó una revisión con respecto al tema consultándose 11 referencias bibliográficas de prestigiosas revistas científicas con un alto grado de actualidad que nos permitió redactan tres habilidades fundamentales como son: Estrategia, la cual involucra a 5 elementos en secuencia; objetivo, contexto, actores, factores y acciones; Comunicación, cuyo proceso además de tener en cuenta las de tipo horizontal, descendente y ascendente, valora la habilidad de la buena escucha y el Trabajo en Equipo, en la que predomina el método interactivo y el enfoque participativo para el buen desarrollo de dicha empresa.

Palabras Claves: Administración Pública; Estrategia; Trabajo en Equipo; Comunicación. 


\section{Habilidades directivas fundamentales en la administración pública}

Vol. 3, núm. 3 Esp., (2019)

Washington Enrique Pazmiño Gavilánez; Mariella Ginela Parrales Higuera; Lorena Isabel Muñoz Oviedo; Veronica Alexandra Merchan Jacome

\section{ABSTRACT}

A conceptual analysis of the terms is developed for didactic purposes; Management, Management, Direction, Governance, Management and Administration, for the good development, survival and integration of a company to the competitive market, a review was made regarding the subject by consulting 11 bibliographical references of prestigious scientific journals with a high degree of present that allowed us to write three fundamental skills such as: Strategy, which involves 5 elements in sequence; objective, context, actors, factors and actions; Communication, whose process in addition to taking into account the horizontal, top-down and bottom-up ones, values the ability of good listening and Teamwork, in which the interactive method and the participative approach predominate for the good development of said company.

Key Words: Public administration; Strategy; Teamwork; Communication. 


\section{Habilidades directivas fundamentales en la administración pública}

Vol. 3, núm. 3 Esp., (2019)

Washington Enrique Pazmiño Gavilánez; Mariella Ginela Parrales Higuera; Lorena Isabel

Muñoz Oviedo; Veronica Alexandra Merchan Jacome

\section{Introducción.}

"Dirigir no es más que obtener resultados a través de otros (a los que dirigimos) o lograr que hagan las cosas que queremos que hagan".

Peter Drucker

Comenzamos un destacado e intenso tema de las Habilidades gerenciales fundamentales, para todo directivo que labore en empresas o instituciones de la Administración Pública. Con esta frase de Peter Drucker queremos llegar a la interpretación de la misma, que sugiere que la dirección, gestión, administración, gerencia, managment y gobernanza o gobernación, hacen las cosas con las personas para obtener los mejores resultados.

Se hace referencia a estos términos que en la práctica resultan sinónimos; al reflexionar sobre sus orígenes recoge la bibliografía, que desde principios del siglo XX tales vocablos han venido siendo empleados como forma de traducir al español el término "Management", acuñado por el norteamericano Frederic Winslow Taylor (1856-1915) definido en 1911 en su obra The Principles of Scientific Management. Por otra parte, el francés Henri Fayol (1841-1925) tituló su primer libro como: Administration Industrialle et Général que se tradujo en 1929 al idioma inglés pero no utilizaron administration como parecía lógico, sino Management; así fue partiendo de ahí en adelante, el empleo de uno u otro término, tanto en inglés como en español, francés o portugués, varió según el país, sus tradiciones o sus especialistas.

En el Continente Americano existen variadas tendencias del uso de este término, en algunos países prefieren el término en inglés, pero en otros, el de administración, aun con el 


\section{Habilidades directivas fundamentales en la administración pública}

Vol. 3, núm. 3 Esp., (2019)

Washington Enrique Pazmiño Gavilánez; Mariella Ginela Parrales Higuera; Lorena Isabel Muñoz Oviedo; Veronica Alexandra Merchan Jacome

peligro que conlleva su confusión con la Administración Pública, o sustituirlo por el de Dirección, que tiene el inconveniente de confundirlo con una de las funciones del ciclo administrativo, conformado por: planificación, organización, dirección y control, por supuesto, con la condición de ordeno y mando, ya obsoleto en nuestros tiempos. Resumidas cuentas al final, se escoge por todos los de gerencia o gestión, que carece de las desventajas de los anteriores. En este trabajo asumimos los de: gerencia, dirección y administración (Carnota Lauzan, 2013).

En un ambiente de competencia y grandes exigencias como el que se desarrolla actualmente, es fundamental para un directivo desplegar y potencializar las habilidades gerenciales planteadas, estas le permitirían a su empresa a incrementar el éxito y mantenerse en permanente evolución para poder hacerle frente al constante cambio, además le aportaran las herramientas fundamentales para responder una demanda exigente la cual puede estar presente en cualquier sector empresarial y laboral.

\section{Desarrollo.}

A los Gerentes actuales les place lo que hacen, administran y sienten empatía con los demás, desarrollando cada día más capacidades necesarias para afianzar un buen liderazgo junto a sus colaboradores, con capacidad para trabajar en equipo y tomar las decisiones acertadas, resolver con éxito los problemas y conflictos, saber innovar, crear, entre otros factores que hacen posible el logro de metas y objetivos verdaderamente pensados por la organización, basados en la misión y visión de su empresa.

La mayoría de los gerentes exitosos tienen una actitud positivista y competitiva hacia los demás, les gusta lo que hacen y se preparan para adquirir nuevas competencias que lo habiliten 


\section{Habilidades directivas fundamentales en la administración pública}

Vol. 3, núm. 3 Esp., (2019)

Washington Enrique Pazmiño Gavilánez; Mariella Ginela Parrales Higuera; Lorena Isabel

Muñoz Oviedo; Veronica Alexandra Merchan Jacome

para poder enfrentar las situaciones cambiantes. Las competencias se representan a través de un iceberg, encontrándose visiblemente las habilidades y el conocimiento; elementos que son más fáciles de adquirir y desarrollar.

Las habilidades directivas o gerenciales son el punto diferenciador entre los gerentes, que simplemente ordenan, aquellos que ejecutan los procesos administrativos y quienes gracias a sus actitudes, acciones y motivaciones firmes y positivas hacia el trabajo y hacia sus subalternos, contribuyen al bienestar de su comunidad laboral y al clima organizacional de sus empresas.

Las compañías más sobresalientes y exitosas, son aquellas que tienen la presencia luminosa de gerentes, que son personas altamente eficaces y competentes, entrenadas $y$ calificadas en habilidades gerenciales además de un gran sentido de pertenencia.

Las habilidades gerenciales se dividen en tres:

- Habilidades técnicas: referidas a la capacidad en la utilización del conocimiento técnico, teniendo las capacidades de poner en práctica procedimientos en un campo específico; poseer, comprender y aplicar los conocimientos técnicos propios de su área para la industria para la que trabaja en función de su cargo.

- Habilidades conceptuales: Es la capacidad para percibir a la organización de manera integral, reconociendo cada uno de sus elementos y su interrelación, dadas por el enfoque estratégico, ya que posibilitan la percepción del entorno y el diseño de nuevos modelos administrativos y organizacionales, como de estrategias para el mejoramiento integral. 


\section{Habilidades directivas fundamentales en la administración pública}

Vol. 3, núm. 3 Esp., (2019)

Washington Enrique Pazmiño Gavilánez; Mariella Ginela Parrales Higuera; Lorena Isabel Muñoz Oviedo; Veronica Alexandra Merchan Jacome

- Habilidades sociales o humanas: explicadas estas como las que deben presentar los gerentes para trabajar, guiar, persuadir y/o motivar a otras personas sin la distinción de rango, género, edad o condición social, a favor de la consecución de los objetivos empresariales. (Gómez Durán, 2014)

Varios son los expertos en esta materia los que incorporan diferentes habilidades: Cito: (Ruiz Rojas), plantea 6 más relevantes: Rol del Liderazgo Conveniente, Empowerment, La promoción y el desarrollo del personal, La comunicación eficaz, Manejo de conflictos y Negociación.

Corbin, hace el planteamiento de las 12 más importantes:

[1] Toma de decisiones

[2] Autoconfianza, interpretada como confianza en si mismo.

[3] Autoconocimiento, interpretado como conocimiento de uno mismo

[4] Gestión de los problemas, referido a los conflictos que conllevan a un problema.

[5] Asertividad, habilidad de expresar la opinión de uno mismo de forma correcta.

[6] Regulación emocional, conocimiento de saber controlar sus emociones, es propia de los buenos gerentes

[7] Resiliencia, disposición de afrontar los cambios, habilidad de adaptación a estos.

[8] Liderazgo, capacidad del líder de influir en los demás. 
Habilidades directivas fundamentales en la administración pública

Vol. 3, núm. 3 Esp., (2019)

Washington Enrique Pazmiño Gavilánez; Mariella Ginela Parrales Higuera; Lorena Isabel

Muñoz Oviedo; Veronica Alexandra Merchan Jacome

[9] Capacidad de delegar

[10] Empatía: Es la sintonía de afectividad con las demás personas y el entorno

[11] Visión y pensamiento estratégico: Es en la que debe estar claro dónde está y hacia dónde se dirige su empresa o sistema organizacional

[12] Habilidades Sociales y Comunicativas. (Ruiz Rojas, 2013), (Cobin, 2018)

Codina, agrupa en 10 estas habilidades directivas: Estrategia, Comunicación, Conflictos, Toma de decisión, Negociación, Trabajo en equipo, Liderazgo y motivación, Administración del tiempo y delegación, Cultura organizacional y Gestión del cambio.

Por la extensión de este trabajo, solo abordaremos las más identificadas dentro de las habilidades directivas definidas por este autor; para mejor interpretación y comprensión de estas habilidades hacemos una referencia implementada en este modelo. (Grafico 1) 


\section{Habilidades directivas fundamentales en la administración pública}

Vol. 3, núm. 3 Esp., (2019)

Washington Enrique Pazmiño Gavilánez; Mariella Ginela Parrales Higuera; Lorena Isabel Muñoz Oviedo; Veronica Alexandra Merchan Jacome

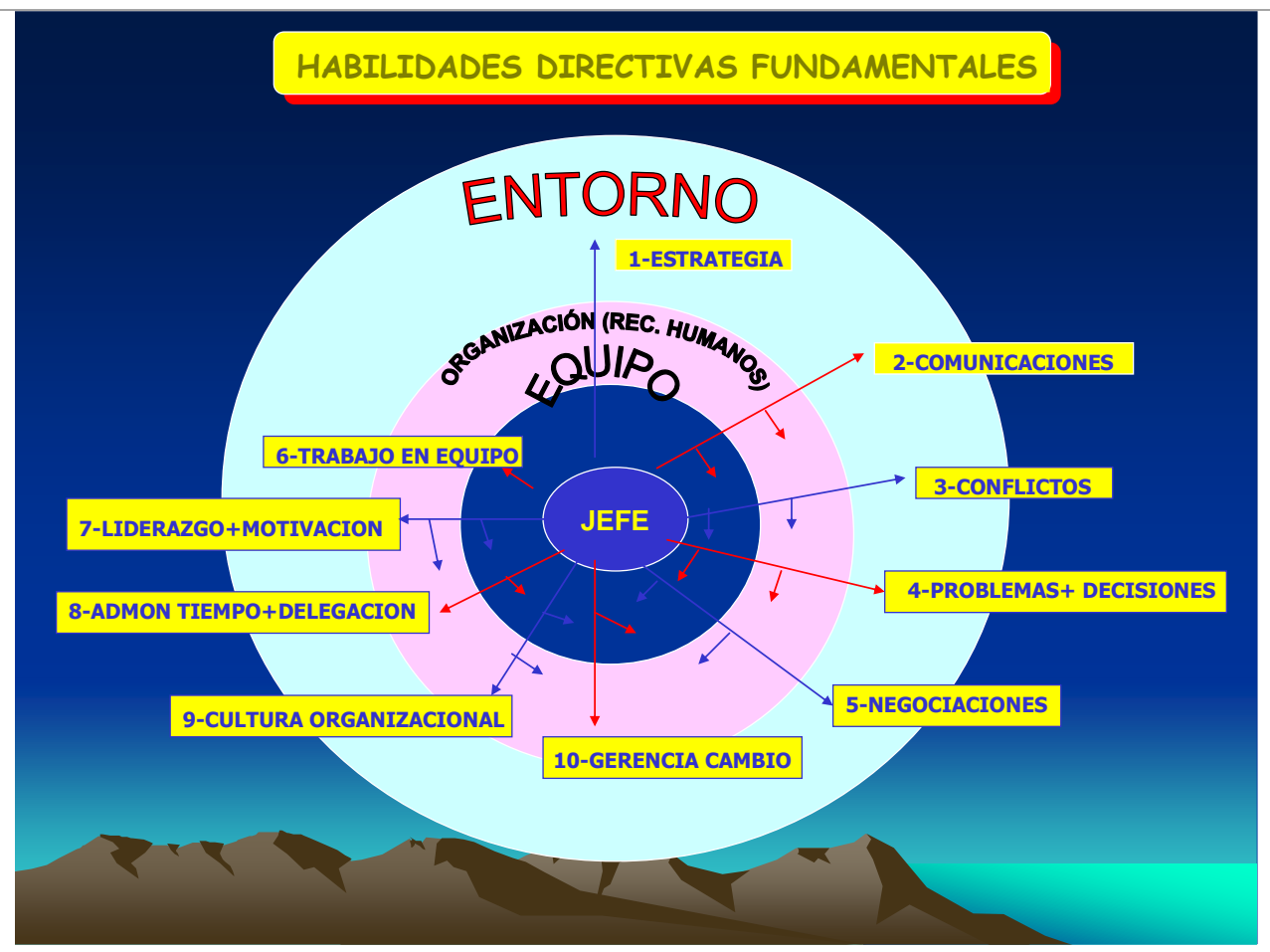

Grafico 1 Tomado de Alexis Codina

\section{Estrategia}

Su origen data en el arte militar (etimológicamente proviene de la palabra griega estrategos y de la fusión de dos palabras: stratos (ejército) y agein (conducir, guiar); declarada como: conjunto general de maniobras realizadas para superar un enemigo durante un combate del área militar), luego expandido al sector público, donde pierde su dimensión más relevante; "el arte de pensar estratégicamente". Cito: (por Igor Ansoff, en su libro "La Estrategia de la Empresa"), este un científico estadounidense, quien fue el pionero en utilizar éste término (1976), diciendo; es "la dialéctica de la empresa con su entorno", considerado desde entonces el padre de la Administración estratégica. Aunque otras literaturas hacen referencia a: Chandler (1962), Andrews (1977), Hofer (1976) y Hofer y Shendel (1978); como sus iniciadores, en ese mismo orden. 


\section{Habilidades directivas fundamentales en la administración pública}

Vol. 3, núm. 3 Esp., (2019)

Washington Enrique Pazmiño Gavilánez; Mariella Ginela Parrales Higuera; Lorena Isabel

Muñoz Oviedo; Veronica Alexandra Merchan Jacome

Estrategia es la habilidad para dirigir un asunto y lograr un objetivo, (Según el diccionario Larousse de la lengua española), por lo que queda definida como un conjunto de acciones organizadas para orientar a la institución al logro de los objetivos.

Muchas definiciones del concepto de estrategia son objeto de especulaciones, presumiendo esto que no hay una definición universalmente aceptada sobre el mismo. Referentes consultados opinan que; los consultores, las empresas privadas y escuelas de negocio y administración, hablan de estrategia, sino de la estrategia; para ellos, la estrategia es aquello, que diferencia una empresa de otra, aportándole una calidad y/o capacidad especial que las otras no tienen, y que la hace exitosa en la competencia con las demás. Siguiendo esta concepción, interpretamos que cada empresa tiene o debe desarrollar su estrategia; comprendida y manejada como la estrategia; por lo que cada empresa tiene o debería tener una estrategia, y solamente una, que será reemplazada por otra, cuando la actual pierda su vigencia. La estrategia única no existe, esto, es a lo que se refieren los del sector privado, es confundible con la identidad general de la organización.

La reflexión medular es sobre el arte de desarrollar estrategias institucionales para el logro de los objetivos institucionales; el objetivo institucional es necesariamente un objetivo de competencia hacia fuera de la organización; el cual forma parte de la contribución de ésta al entorno, aportando directamente al cumplimiento de su misión. Toda estrategia involucra a 5 elementos en secuencia; objetivo, contexto, actores, factores y acciones; pudiéndose asumir que la estrategia institucional se puede conceptualizar como un proceso de interacción social, que está orientado por una configuración alternativa y dinámica de momentos y macropasos, donde se articulan actores, factores y acciones, para el logro de un objetivo institucional, en un determinado contexto que afecta a ambos, estrategia y objetivo y que, a su vez, es afectado por ellos. 


\section{Habilidades directivas fundamentales en la administración pública}

Vol. 3, núm. 3 Esp., (2019)

Washington Enrique Pazmiño Gavilánez; Mariella Ginela Parrales Higuera; Lorena Isabel Muñoz Oviedo; Veronica Alexandra Merchan Jacome

En revisiones conceptualizadas al respecto, de varios autores, se revela que; la estrategia se refiere al patrón de aplicación de recursos organizacionales a los efectos del alcance de los objetivos propuestos en su formulación que debe tener reflejada que la estrategia es considerada como la fuerza conductora de la organización, por lo que deben tener en cuenta tres importantes aspectos; la relación producto-mercado, las capacidades y los resultados. (De Sourza, Cheaz Pelaez, Santamaria Guerra, \& Mato Bode, 2001), (Conde Lorenzo \& Labrador Orraca, 2013)

Asumiendo e interpretando una visión económica del mundo, relacionando la organización como un proveedor para el mercado competitivo, se enmarca que las estrategias estarán asociadas a objetivos orientados al incremento de la competitividad de la organización en general y algunas actividades en particular, por lo que es así que la definición de una estrategia competitiva avisora en desarrollar una amplia fórmula de ¿cómo la empresa va a competir?, ¿cuáles deben ser sus objetivos? y ¿que políticas serán necesarias para alcanzar tales objetivos?.

Por otro lado, Mintzberg et al (1997), define a la estrategia empresarial como un plan integrado por las principales metas y políticas de una organización

Estableciendo a su vez, la secuencia coherente de las acciones a realizar; alista que una buena estrategia ayuda a poner orden y asignar con base, tanto en sus atributos como en sus deficiencias internas, los recursos de una organización para el logro de una situación viable y original; así como anticipar posibles cambios en el entorno y las acciones imprevistas de sus oponentes inteligentes. También se alude que dentro de las estrategias empresariales están las llamadas Estrategias Competitivas (Porter, 1982, 1999); explica que estos buscan posicionar a la empresa para llegar al máximo, el valor de las capacidades que la distinguen de sus competidores, 


\section{Habilidades directivas fundamentales en la administración pública}

Vol. 3, núm. 3 Esp., (2019)

Washington Enrique Pazmiño Gavilánez; Mariella Ginela Parrales Higuera; Lorena Isabel

Muñoz Oviedo; Veronica Alexandra Merchan Jacome

significando entonces; elegir deliberadamente un conjunto de actividades diferenciadas y ofrecer una combinación única de valor. interesante resulta la incorporación de una visión filosófica de gestión basada en la estrategia, según varios autores; si se integra visión, misión, objetivos, principios, valores, estrategias y formas de planificación, que posea cualquier empresa; queda reflejado aquí el origen del uso de la Planificación estratégica en los sistemas organizacionales. (Ferrer \& Caterina, 2006)

En las estrategias de negocios, en lo que a negocio se trata; deja expresado que es indispensable su presencia en los mismos para poder mantenerse en el mercado su presencia con otras. Existen cuatro tipos de estrategias de negocios:

- Estrategia de crecimiento: Su implicación está en la introducción de nuevos productos o la adición de nuevas características para los productos ya existentes, ejemplificando, en las compañías de teléfonos celulares constantemente añaden nuevas características o descubriendo dispositivos de nuevas tecnologías; estas compañías que no se mantengan al día con la demanda de los consumidores, no permanecerán en el negocio por mucho tiempo.

- La diferenciación del producto: Pequeñas empresas tienen la constante de utilizar una estrategia de diferenciación de los productos, cuando tienen ventaja competitiva; digamos, como la calidad o un servicio superior, mencionamos; un pequeño fabricante de purificadores de aire, pueden diferenciarse de los competidores con su diseño de ingeniería superior. 


\section{Habilidades directivas fundamentales en la administración pública}

Vol. 3, núm. 3 Esp., (2019)

Washington Enrique Pazmiño Gavilánez; Mariella Ginela Parrales Higuera; Lorena Isabel Muñoz Oviedo; Veronica Alexandra Merchan Jacome

- El precio diferenciado: Estrategia utilizada en una pequeña empresa para recuperar vertiginosamente su producción y los gastos de publicidad, cabe presuponer, que tiene que haber la presencia de algo especial en el producto elaborado, para que los consumidores paguen el precio exorbitante publicado; digamos una pequeña empresa puede ser la primera en la introducción de un nuevo tipo de panel solar; como la empresa es la única que vende el producto; los clientes que realmente quieren los paneles solares pueden pagar el precio más alto.

- Estrategia de adquisición: Infiere la compra de otra empresa, o de una o más líneas de los productos de dicha empresa, digamos, un minorista de abarrotes en una región del este, puede comprar una cadena de supermercados comparable en el medio oeste para expandir sus operaciones.

\section{Comunicación}

Son muy variados, en las literaturas especializadas consultadas, los antecedentes etimológicos acerca del concepto de comunicación; pero el concepto significativo arroja en su esencia, la estrecha relación que existe comunicarse $\longleftrightarrow \ldots$ y estar en comunidad; quedando definido que se está en comunidad; porque se pone de manifiesto algo en común a través de la comunicación.

Para dejar declarado específicamente este concepto, asumimos la definición representada en el modelo (Shannon-Wiener); que a fines de los años cuarenta se dio a conocer, como el Proceso de la Comunicación; 
Habilidades directivas fundamentales en la administración pública

Vol. 3, núm. 3 Esp., (2019)

Washington Enrique Pazmiño Gavilánez; Mariella Ginela Parrales Higuera; Lorena Isabel

Muñoz Oviedo; Veronica Alexandra Merchan Jacome

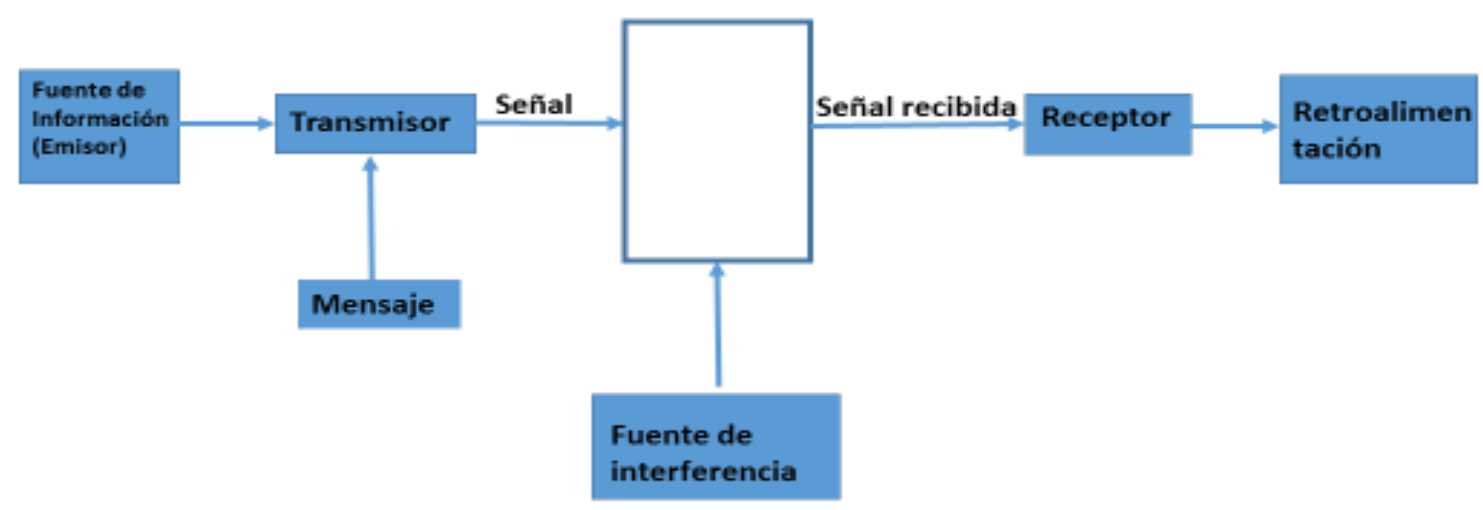

Grafico 3. Modelo de Shannon-Wiener

Tomado de: Interpretación realizada de la forma siguiente, lo cual se propone el uso y definiciones frecuentes como: Emisor, Código, Mensaje, Transmisor, Receptor y Retroalimentación.

- Emisor: puede tratarse de cualquier individuo interno o externo de una organización o empresa, siendo la fuente de comunicación o información, quien desea transmitir un pensamiento o idea a otro u otros. En el caso de una empresa podría tratarse del gerente, secretaria, obrero, cliente, además que tenga necesidad de transmitir una información relacionada con los servicios, sucesos, etc. que ocurra en la empresa. 


\section{Habilidades directivas fundamentales en la administración pública}

Vol. 3, núm. 3 Esp., (2019)

Washington Enrique Pazmiño Gavilánez; Mariella Ginela Parrales Higuera; Lorena Isabel Muñoz Oviedo; Veronica Alexandra Merchan Jacome

- El código: se refiere a la forma en que se codificará ese pensamiento, que incluyen la habilidad, la actitud, los conocimientos, además del sistema sociocultural, apuntamos que, el éxito total de cada persona está determinado por las habilidades de hablar, escribir, escuchar y razonar.

- El mensaje; es el producto real de la fuente codificadora, es toda información que se transmite y si se logra una comunicación exitosa, será también todo lo recibido por el receptor.

- El canal o transmisor: es la vía a través de la cual transita el mensaje, ‘por lo que en una organización y en cualquier situación es muy importante seleccionar la vía más adecuada para transmitir la información, dependiendo esta del tipo de información; de quienes deberán recibirlo; las condiciones que se requieren para el mejor entendimiento del mismo, tradicionalmente siguen la red de autoridad de una organización los mensajes relacionados con el trabajo de los miembros de la misma, por lo que para esto, lo más adecuado posible es un canal formal.

- El receptor: objeto a quien se dirige el o los mensajes, antes de que esto ocurra el mensaje debe ser descodificado; proceso que requiere de las habilidades, actitudes y conocimientos previos sobre el tema que informa el receptor.

- La retroalimentación: indica en el proceso de la comunicación si hubo éxito; en una organización se mide si una información llegó adecuadamente si se recupera respuesta ante el mismo. 


\section{Habilidades directivas fundamentales en la administración pública}

Vol. 3, núm. 3 Esp., (2019)

Washington Enrique Pazmiño Gavilánez; Mariella Ginela Parrales Higuera; Lorena Isabel Muñoz Oviedo; Veronica Alexandra Merchan Jacome

Existen las barreras (interferencias) durante el proceso de comunicación que pueden presentarse en cualquiera de sus momentos:

- Psicológicas, derivadas de la actitud o comportamiento de las personas.

- Semánticas, las que se originan por el mal uso del lenguaje.

- Lingüísticas, se producen por el uso de códigos en que el receptor no está

- familiarizado, Ejemplo, desconocimiento del idioma

- Físicas, dada por las influencias del medio socio-ambiental. Ejemplo el ruido

- Fisiológicas, sus consecuencias son por problemas del cuerpo humano. Ejemplo

- sordera

- Administrativas, obstáculos en el buen funcionamiento de la empresa.

Según Cisneros, existen tres elementos básicos de la comunicación:

- La persona que habla (Quién)

- El discurso que pronuncia (Qué?)

- La persona que escucha ¿A quién?

La efectividad de la comunicación, se loga con lo más importante que es la capacidad de la escucha empática, existiendo para esto 2 reglas básicas a tener en cuenta:
Las 3 "Q"
Las $3{ }^{\prime \prime} \mathrm{C} "$

- Que comunicar

Cuando comunicar

- Quien da la información

Como comunicar 


\section{Habilidades directivas fundamentales en la administración pública}

Vol. 3, núm. 3 Esp., (2019)

Washington Enrique Pazmiño Gavilánez; Mariella Ginela Parrales Higuera; Lorena Isabel Muñoz Oviedo; Veronica Alexandra Merchan Jacome

\section{- A quien se le va a comunicar Cuanto comunicar}

El experto Huerta Mata expone un consejo útil: procurar primero comprender y después ser comprendido; este principio es la clave del éxito de la comunicación interpersonal efectiva, ya que generalmente las personas en las organizaciones están acostumbradas a escuchar y recibir información sin la intención de comprender, es por ello que la escucha empática se hace primordial al momento de retroalimentar a los subordinados y comprender sus necesidades personales así como laborales.

Acotamos que en el proceso de la comunicación, es incluida la habilidad de escuchar; afirmamos que no es lo mismo oír que escuchar; oír es considerado un proceso fisiológico pasivo, es una cuestión de capacidad sensorial, mientras que escuchar es un proceso activo de mayor complejidad que implica la debida atención, interés por nuestro interlocutor lo que involucra la percepción, la comprensión y otros procesos mentales.

La escucha activa, tiene su significación en escuchar y entender la comunicación desde el punto de vista del hablante, mientras que la escucha efectiva tiene que ser imprescindiblemente activa por encima de lo pasivo. La habilidad de escuchar, se refiere no solo a lo que la persona está expresando directamente sino a los sentimientos, ideas, pensamientos que están bajo de lo que se está diciendo.

(Sánchez Jacas, Espino La O, Elias Ramirez, Pineda Tamayo, \& Raffa, 2013) , _(Duarte Rodríguez, 2013) 


\section{Habilidades directivas fundamentales en la administración pública}

Vol. 3, núm. 3 Esp., (2019)

Washington Enrique Pazmiño Gavilánez; Mariella Ginela Parrales Higuera; Lorena Isabel

Muñoz Oviedo; Veronica Alexandra Merchan Jacome

Flujo de la comunicación en la organización

La eficacia de las habilidades de comunicación se enmarcan extremadamente necesarias dentro de cualquier tipo de organización, ésta comunicación administrativa efectiva, es un proceso bidireccional de intercambio de informaciones con un propósito específico; los logros de una empresa, institución, organización o sistema organizacional, están en dependencia del grado de entendimiento que exista entre sus miembros y de la disponibilidad de información que necesiten para hacerlo.

La comunicación empresarial es fundamentada en tres tipos: Horizontal, es entre personas del mismo nivel, tipo de comunicación que se establece entre subordinados - subordinados.

Vertical descendente: esta parte de un nivel jerárquico superior a un nivel inferior, es la establecida entre jefe - subordinado.

Vertical ascendente: resulta de la comunicación del nivel jerárquico inferior a superiores; subordinado - jefe.

Resumiendo, la comunicación no solo implica ser la habilidad más importante imprescindible, sola es en su máxima expresión, una habilidad que relaciona y atraviesa un conjunto de otras destrezas que necesitan servirse de ellas para lograr los objetivos organizacionales. 


\section{Habilidades directivas fundamentales en la administración pública \\ Vol. 3, núm. 3 Esp., (2019) \\ Washington Enrique Pazmiño Gavilánez; Mariella Ginela Parrales Higuera; Lorena Isabel Muñoz Oviedo; Veronica Alexandra Merchan Jacome}

\section{Trabajo en equipo}

(Según Carnota), cito: el concepto de equipo, es una extensión del concepto de grupo y ambos se refieren al trabajo de conjunto de varias personas a las cuales las une un objetivo común. Durante toda la evolución y desarrollo de la humanidad los equipos y grupos han existido; actualmente el termino de equipo es identificado como forma más avanzada del trabajo con los grupos, ya que expresa un crecimiento de la empresa con productos y servicios de mayor calidad y capacidad que permiten vencer a sus competidores; en estos nuevos grupos, donde se unen la inteligencia y la acción e integran las fuerzas psicológicas implicadas, se observa el desarrollo y el uso de las técnicas de dinámica de grupo, como son; las centradas en generar ideas y estimular la creatividad; técnicas encaminadas en alcanzar consenso u organizar las ideas; técnicas de solución de problemas en grupo y experimentación. Todas estas fueron mejoradas, ampliadas y aplicadas por el estudioso del tema (Deming), que infiere elevar el desempeño y la competitividad de las empresas. La denominación de este nuevo término, fue controversial, actualmente unos prefieren mantenerse llamándolo grupo, aunque la mayoría adopta el de equipo; a la escucha, aparecen diversas denominaciones, tales como; equipo autodirigido, equipo verdadero, equipo autogobernado o autoadministrado, equipo de negocio, equipo de alto desempeño entre otros.

En la caracterización de los equipos prevalecen dos condiciones; el método interactivo y el enfoque participativo, que utilizan: Es interactivo porque en esta nueva condición figura el equipo; los miembros del mismo se interrelacionan con una participación activa, plena, y franca, resulta una tarea compleja y difícil tratando de extraer lo mejor, basado en la inteligencia de los participantes en relación a un objetivo, además de lograr resultados con el apoyo y entusiasmo de los miembros. 


\section{Habilidades directivas fundamentales en la administración pública}

Vol. 3, núm. 3 Esp., (2019)

Washington Enrique Pazmiño Gavilánez; Mariella Ginela Parrales Higuera; Lorena Isabel

Muñoz Oviedo; Veronica Alexandra Merchan Jacome

Los fundamentos que sustentan al enfoque participativo son:

- Competencia: los miembros deben estar adiestrados en y para la competencia en el asunto a resolver.

- Juicio diferido: surgimiento de ideas o soluciones alternativas, durante el proceso de creatividad, las cuales no deben estar plagadas de interrupciones o estorbados por el juicio crítico.

- Dinámica de grupo: donde se hace utilización intensa de estas técnicas, que independientemente de su uso, estimulan la comunicación, la interacción y la concentración de los miembros en el objetivo de unión.

- Desarrollo planificado: necesidad de seguir un plan que sea permisible a irse acercando a los resultados momento a momento.

- Contenido y proceso: el primero, es referido al trabajo sobre el objetivo de la reunión, la discusión que se produce, el aporte de las ideas, así como las soluciones por los miembros; el segundo se relaciona con la organización y conducción del trabajo en equipo.

- Consenso: consiste en evitar los acuerdos y decisiones de tipo unipersonal o mediante votación, lo que estimula al consenso como fórmula básica.

- Ambiente: es el entorno físico y psicológico que influye en determinados resultados. (Carnotza Lauzan, 2011) 


\section{Habilidades directivas fundamentales en la administración pública}

Vol. 3, núm. 3 Esp., (2019)

Washington Enrique Pazmiño Gavilánez; Mariella Ginela Parrales Higuera; Lorena Isabel Muñoz Oviedo; Veronica Alexandra Merchan Jacome

El trabajo en equipo. Su Importancia

Es más que una forma de organización en la gerencia empresarial, algunas empresas no obtienen los resultados esperados categóricamente, ya que no logran convocar a todos los agentes que intervienen en ella, su utilización aporta lo siguiente:

1) Creación de sinergias: Cuando se suman a otros los conocimientos individuales, tienen un mayor impacto.

2) Estructuras más flexibles y participativas: Poseen un margen de acción mucho mayor, ya que dependen menos de las jerarquías y sus integrantes, además son el escenario perfecto para el fomento de valores; la solidaridad, la colaboración mutua así como el sentido de pertenencia hacia el grupo y la empresa en su conjunto.

3) Empoderamiento y responsabilidad: Al formar parte de un grupo las responsabilidades se refuerzan, debido a que cada integrante asumiría un rol dentro del equipo, respondiendo a los demás por las tareas asignadas.

4) Fomenta el desarrollo de habilidades sociales: La condición de encontrarse en entornos más autoritarios y rígidos impiden el desarrollo de habilidades sociales, como; la empatía, la comunicación eficaz, la resolución de conflictos, entre otros,

5) Fortalecimiento a las empresas ante el cambio: Los efectos interrelacionados hacen más fuertes a las empresas ante los cambios o las amenazas que puedan ser obstáculos para sus objetivos. 


\section{Habilidades directivas fundamentales en la administración pública}

Vol. 3, núm. 3 Esp., (2019)

Washington Enrique Pazmiño Gavilánez; Mariella Ginela Parrales Higuera; Lorena Isabel

Muñoz Oviedo; Veronica Alexandra Merchan Jacome

Características del trabajo en equipo. (Según Guatelli), Se refiere a, Cito:

La integración armónica de funciones y actividades desarrolladas por diferentes personas. Su implementación requiere que las responsabilidades se compartan entre sus miembros. Necesidad de que las actividades a desarrollar se realicen en forma coordinada. Es necesario que los programas que se planifiquen en equipo se centralicen en un objetivo común.

Concluyendo con acierto; que un equipo es caracterizado por el cumplimento de todos los aspectos descritos como son; el uso del método interactivo y el enfoque participativo; integración; compromiso; además de responsabilidad y planificación de un grupo dado. (Guatelli, 2007)

Consideraciones finales

A pesar de que cada una de las habilidades gerenciales es diferente; no pueden separarse una de otras, pues forman un sistema integrado, armónico y coherente con la persona, el medio y las diversas situaciones que son de cada día en toda institución.

Todas, como sistema al fin que son; están interconectadas, la lógica precisa que no se puede establecer una estrategia sin comunicación, ni trabajo en equipo de los miembros de la organización. De gran importancia es generar y desarrollar estrategias que permitan la multiplicación y mejoramiento continuo de estas habilidades. 


\section{Habilidades directivas fundamentales en la administración pública}

Vol. 3, núm. 3 Esp., (2019)

Washington Enrique Pazmiño Gavilánez; Mariella Ginela Parrales Higuera; Lorena Isabel Muñoz Oviedo; Veronica Alexandra Merchan Jacome

\section{Bibliografía.}

Carnota Lauzan, O. (2013). Hacia una conceptualización de la gerencia en salud de las particularidades . Recuperado el 6 de septiembre de 2018, de Revista Salud Pública.39(3): http://www.revsaludpublica.sld.cu/index.php/spu/article/view/10/97

Carnotza Lauzan, O. (2011). Gerencia sin agobio.Un aporte a la eficiencia personal. La Habana .Cuba: Editorial Ciencias Médicas.

Cobin, J. A. (2018). Habilidades gerenciales:12 claves para el éxito empresarial. Recuperado el 30 de agosto de 2018, de Empresa. Psicología y Mente: https://psicologiaymente.com/empresas/habilidades-gerenciales

Conde Lorenzo, E., \& Labrador Orraca, L. (2013). Consideraciones teóricas para la consecución de estrategias educativas de desarrollo sociocultural para la Educación Popular Ambiental de la comunidad. Recuperado el 10 de septiembre de 2018, de Revista Caribeña de Ciencias Sociales : http://caribeña.eumed.net/educacion-popularambiental/

De Sourza, S. J., Cheaz Pelaez, J., Santamaria Guerra, J., \& Mato Bode, M. A. (2001). La dimensión de estrategia en la construcción de la sostenibilidad institucional. Recuperado el 20 de agosto de 2018, de Serie Innovación para la sostenibilidad Institucional .San José Costa Rica. Proyecto ISNAR "Nuevo Paradigma": https://conexionsurmza.files.wordpress.com/2012/08/la-dimensic3b3n-de-gestic3b3n-enla-construccic3b3n.pdf

Duarte Rodríguez, A. C. (2013). Habilidades gerenciales y su importancia para el exito de uan organización .Universidad Militar Nueva Granada .Bogotá D.C .Colombia . Recuperado el 10 de septiembre de 2018, de https://repository.unimilitar.edu.co/bitstream/10654/10099/2/DuarteRodriguezAnaConsta nza2013.pdf

Ferrer, J., \& Caterina, C. (2006). Habilidades gerenciales como fundamento de la estrategia competitiva en los sectores de actividad metalmecánica venezolana. Recuperado el 8 de septiembre de 2018, de TENDENCIAS https://dialnet.unirioja.es/descarga/articulo/3985408.pdf

Gómez Durán, L. A. (2014). Competencias y habilidades gerenciales que deben desarrollar un buen lider. Recuperado el 3 de septiembre de 2018, de Trabajo de Grado.Universidad Militar Nueva Granada: https://repository.unimilitar.edu.co/bitstream/10654/11761/1/TRABAJO\%20DE\%20GR ADO\%20FINAL\%20COMPETENCIAS\%20Y\%20HABILIDADES\%20GERENCIALE S.pdf 


\section{Habilidades directivas fundamentales en la administración pública}

Vol. 3, núm. 3 Esp., (2019)

Washington Enrique Pazmiño Gavilánez; Mariella Ginela Parrales Higuera; Lorena Isabel

Muñoz Oviedo; Veronica Alexandra Merchan Jacome

Guatelli, M. (2007). Trabajo en Equipo. Recuperado el 9 de agosto de 2018, de Revista Ser $\begin{array}{llll}\text { Mejores No } & 1 & \text { Marzo }\end{array}$ http://www.repositorio.ucm.edu.co:8080/../Alba\%20Rocio\%20Martinez\%20Goez.pdf?

Ruiz Rojas, P. A. (2013). Las habilidades gerenciales y su importancia en la dirección empresarial. Recuperado el 31 de agosto de 2018, de Revista M\&M: https://revista$\mathrm{mm}$.com/blog/administracion/las-habilidades-gerenciales-y-su-importancia-en-ladireccion-empresarial/

Sánchez Jacas, I., Espino La O, Z., Elias Ramirez, A. L., Pineda Tamayo, Y., \& Raffa, M. (2013). Autoevaluación de la habilidad de saber escuchar en directivos de salud .Provincia Santiago de Cuba. Recuperado el 9 de septiembre de 2018, de Revista de Información Cientifica para los directivos de salud INFODIR 16 : http://www.revinfodir.sld.cu/index.php/infodir/article/view/5/9

$$
\text { (C) (1) } \Theta(0)
$$

RECONOCIMIENTO-NOCOMERCIAL-COMPARTIRIGUAL

CC BY-NC-SA

ESTA LICENCIA PERMITE A OTROS ENTREMEZCLAR, AJUSTAR Y CONSTRUIR A PARTIR DE SU OBRA CON FINES NO

COMERCIALES, SIEMPRE Y CUANDO LE RECONOZCAN LA AUTORÍA Y SUS NUEVAS CREACIONES ESTÉN BAJO UNA LICENCIA CON LOS MISMOS TÉRMINOS. 